\title{
ARTICLE \\ Makran Coastal Zoning for the Construction of New Marine Areas based on Hydrological and Hydraulic Characteristics Using Satellite Data and Spatial Analysis
}

\author{
Hossein Khanzadi $^{*}$ Karim Akbari Vakilabadi $^{1}$ Ramin Almasi $^{2}$ \\ 1. Department of marine faculty, Imam Khomeini Maritime University, Nowshahr, Iran \\ 2. M.Sc. of Civil engineering, Tabriz University of Technology, Tabriz, Iran
}

\section{ARTICLE INFO}

Article history

Received: 5 March 2021

Accepted: 31 March 2021

Published Online: 31 March 2021

Keywords:

Makran coasts

Multi-criterion decision analysis

Zoning

Local data base

\begin{abstract}
On one hand, the diversity of activities and on the other hand, the conflicts between beneficiaries necessitate the efficient management and supervision of coastal areas. Accordingly, monitoring and evaluation of such areas can be considered as a critical factor in the national development and directorship of the sources. With regard to this fact, remote sourcing technologies with use of analytical operations of geographic information systems (GIS), will be remarkably advantageous. Iran's south-eastern Makran coasts are geopolitically and economically, of importance due to their strategic characteristics but have been neglected and their development and transit infrastructure are significantly beyond the international standards. Therefore, in this paper, with regard to the importance of developing Makran coasts, a Multi-Criterion Decision Analysis (MCDA) method was applied to identify and prioritize the intended criteria and parameters of zoning, in order to establish new maritime zones. The major scope of this study is to employ the satellite data, remote sensing methods, and regional statistics obtained from Jask synoptic station and investigate the region's status in terms of topography, rainfall rate and temperature changes to reach to a comprehensive monitoring and zoning of the coastal line and to provide a pervasive local data base via use of GIS and MCDA, which will be implemented to construct the coastal regions.

In this article, while explaining the steps of coastal monitoring, its main objectives are also explained and the necessary procedures for doing so are presented. Then, the general steps of marine climate identification and study of marine parameters are stated and the final achievements of the coastal monitoring process are determined. In the following, considering that this article focuses on the monitoring of Makran beaches, the method of work in the mentioned region will be described and its specific differences and complexities will be discussed in detail. Also, the impact of such projects on future research results will be discussed.
\end{abstract}

*Corresponding Author:

Hossein Khanzadi,

Department of marine faculty, Imam Khomeini Maritime University, Nowshahr, Iran;

Email: hk.patriot6@gmail.com 


\section{Introduction}

Makran beaches as one of the most important aquatic habitats in the country have been strategically neglected due to the lack of a comprehensive and integrated management approach in recent years. In order to manage the strategic area of Makran, the use of satellite data and spatial analysis provides us with valuable information for a comprehensive monitoring. However, the spatial information of many of the world's aquatic habitats is considered to be one of the main unknowns in the study of water resources. For reasons such as high costs and lack of necessary equipment, Makran beaches lack accurate information on spatial changes, which is one of the main limitations of this study.

The effects and natural phenomena of the earth's surface are changing rapidly, and these changes are remarkable throughout human life ${ }^{[1]}$. One important point is that these changes can be carefully reviewed so that natural and human factors recognize these changes; therefore, coastal areas, the lake interior, lake fluctuations and other important parameters are considered as ecological environments ${ }^{[2]}$. In this context, monitoring and evaluating such areas can be considered as an important issue in national development and water resource management. With the advancement of marine science and technology and stakeholder engagement, it is possible to solve the problems ${ }^{[3]}$. Marine and coastal studies provide decision makers with plenty of information to manage coastlines. Existing regional management plans for regional sustainable development in coastal areas do not provide the intended purpose for the construction of new offshore areas ${ }^{[5]}$. To ensure the sustainable development of offshore areas, the conservation of coastal resources is a requirement ${ }^{[6]}$. It is not clear to the departments and developers of the new maritime areas which areas can be used for offshore projects, MFZ method can be used to clarify many issues ${ }^{[7]}$. Thus, over the past few decades, the use of measuring technology to detect such changes over time has attracted the attention of various researchers ${ }^{[8]}$.

Understanding natural potential, including the climate of each region as the basis for human activities, forms the basis of environmental planning. Earth warming research provides an important insight into the response to terrestrial ecosystems ${ }^{[9]}$. Lack of knowledge of the sub-regions of the regions, causes the economic and agricultural planning fail. For this reason, the importance and necessity of identifying homogeneous climatic regions has long been of concern to geographers and climatologists, and has led to the development of diverse climatological methods such as Sylaninov, Hansen, Coupon, De Martonne, Embereger, etc. Makran coast in the southeast of Iran is of geopolitical, geostrategic and geo-economic importance due to its strategic location and characteristics. The existence of a free trade-economic zone in Chabahar, the existence of suitable beaches, land and proper shelter along the coast, the existence of excellent platforms for transit and shipping, the presence of small bays (banks), the presence of coasts with adequate defense capabilities, the proximity to free waters and the proper operational depth Oman Sea, the presence of naval areas of the army, the existence of the necessary conditions for the expansion of military units and the adaptation of the military area by political divisions are part of the capabilities of the region, but over the past decades, due to more focus on Gulf ports and beaches, these capabilities have not been used. Makran's lanes are not only the most developed Iranian seaboard, but also on the basis of development indicators, this axis is among the most rebellious areas in Iran. However, the future development of the country, especially in the Middle East, depends to a large extent on the geographical and coastal situation of the Oman Sea. Considering the above, fertilizing the capabilities of these important beaches will increase Iran's geopolitical weight in the region and even in the world. Zoning is an appropriate tool for guiding the use of sustainable regions, and its growing effectiveness is undeniable among scholars ${ }^{[10]}$. Zoning is an approach that can provide a good prospect for researchers to explore different areas for human activities ${ }^{[11]}$. It shows the zoning of marine activities in different regional scales ${ }^{[12]}$.

Marine spatial planning (MSP) is increasingly considered an effective tool that can resolve conflicts among various human uses as well as the conflicts between human uses and the marine environment. Many countries such as Australia, United Kingdom, Germany, Belgium, and United States have already initiated or implemented MSP. In China, marine functional zoning (MFZ) has developed independently since it was first proposed by the Chinese government in $1988^{[14]}$

In marine protected areas (MPAs), zoning schemes can help balance multiple resource uses. Literature on ocean zoning design methods points out the need for analytical tools that guarantee stakeholder involvement and that address the unique spatial characteristics of the sea, especially under multiple jurisdictions ${ }^{[15]}$.

To showcase the contribution of MFZ as a practical approach for Xiamen integrated coastal management (ICM) ${ }^{[16]}$, the five dimensions of integration in ICM are applied as an analysis framework. Firstly, through compiling of the historical data and documents of the sea uses and marine environments, and socioeconomic status as well, the key drivers of initiating MFZ in the 1990s is summarized 
as increasing but incompatible and even conflicting sea uses, degrading marine environments due to negative effects of intensified human activities, and the lack of coordinating mechanism which has worsened the use-use and use-environment conflicts. Secondly, the technical guidelines and adaptive evolvement of Xiamen MFZ is introduced, and the achievements of Xiamen MFZ are explored. Based on the above analysis, the relationships of MFZ and ICM is looked into the dimensions of legislation, coordinating mechanism, scientific and technical support, integrated law enforcement and public participation; and how MFZ contributes to ICM in integration of dimensions of intergovernmental, inter-sectoral, land and sea, science and management, and multiple disciplinary is analyzed in-depth ${ }^{[16]}$.

By collecting thin sections, the sediments of the area are studied and their types are determined. Finally, combining these two sources of information, potentially suitable and unsuitable areas for the construction and development of jetties, ports and fuelling jetties are determined. It was shown that factors such as fluctuations in the sea level, tectonic processes, climatic atmosphere, hydraulic processes, especially tidal currents, human interference, and construction activities in the jetties and these coastal regions are the most destructive and constructive forces at work in the coastal regions ${ }^{[17]}$. The morphology of six adjacent major catchments draining the onshore Makran accretionary wedge in southeast Iran and southwest Pakistan was studied to examine how the channel pattern and the length profiles may reflect the recent and active growth of the wedge. Qualitative field surveys were combined with the quantitative analysis of channel steepness and concavity measured from digital elevation models. These profiles were compared with modelled profiles using a stream power approach assuming homogeneously uplifting, uniform rock substratum. Results show a distinct difference between the studied western and eastern catchments ${ }^{[18]}$.

The present study aims to classify the climatic and zoning of Makran coastlines, taking into account parameters such as coastline changes in order to achieve a comprehensive location database for the construction of maritime areas and optimal utilization of the functions of the region.

Table1. Monthly Raining Data from Jask Station

\begin{tabular}{|c|c|c|c|c|c|c|c|c|c|}
\hline \multicolumn{4}{|c|}{ Geographical Location: } & \multicolumn{6}{|c|}{ Jask Station } \\
\hline \multicolumn{4}{|c|}{ Average Monthly Rainfall(mm) } & \multicolumn{6}{|c|}{ Average Monthly Rainfall(mm) } \\
\hline 8 & 2016 & 2 & 2012 & 7.47 & 2008 & 3.33 & 2004 & 1.37 & 2000 \\
\hline 10 & 2017 & 8.63 & 2013 & 7.56 & 2009 & 7.87 & 2005 & 6.04 & 2001 \\
\hline- & - & 12.86 & 2014 & 5.11 & 2010 & 14.74 & 2006 & 2.73 & 2002 \\
\hline- & - & 11 & 2015 & 2.62 & 2011 & 15.09 & 2007 & 1.43 & 2003 \\
\hline
\end{tabular}

Table2. Monthly Temperature Data from Jask Station

\begin{tabular}{|c|c|c|c|c|c|c|c|c|c|}
\hline 27 & 2016 & 27.36 & 2012 & 26.87 & 2008 & 27.96 & 2004 & 27.76 & 2000 \\
\hline- & - & 26.89 & 2014 & 27.73 & 2010 & 27.3 & 2006 & 27.8 & 2002 \\
\hline- & - & 26.1 & 2015 & 24.34 & 2011 & 27.46 & 2007 & 27.74 & 2003 \\
\hline
\end{tabular}




\section{Methods and Material}

The studied area in this research is the Makran coast in southwest of Iran. Makran is approximately consisted of Sistan and Balouchestan and part of south coast of Hormozgan in Iran.

\subsection{Determination of the Studied Area's Climate}

As it is pointed out, climate is one of the most effective phenomena of human life and recognition natural potentials i.e. regional climate is the basis of environmental planning. Hydraulic and hydrological characteristics are different in varied naval regions ${ }^{[13]}$. So in this study to determine the regional climate, required data of temperature and raining are prepared from Synoptic station in the port of Jask (Tables 1 \& 2). Average data of raining and temperature are derived from using interpolation and then using climate determination methods De Martonne and Embereger, the climate of studied region is determined. In De Martonne method determination of climate type is based on yearly raining amount and temperature. In Embereger method which is more sensitive than De Martonne, besides using monthly raining amount, the coldest and hottest temperature of the month is used to determine the climate conditions.

\subsection{Check the Topography and Tilt Status of the Area}

A closer examination of the amount of precipitation and temperature and the subsequent mapping of the Makran coastal strips requires a knowledge of the topographic conditions of the area, because the precipitation varies with the variations in rainfall, and the type of climate in the study area can change. If the altitude changes are taken into account in the estimation of moisture and heat regimes, soil moisture and heat regimes in different regions will be very diverse. In order to investigate the topography status of the present study, we use the GIS techniques to estimate the required maps using the Raster and Wactar data. For this purpose, a 38-meter digital map taken from the ASTER satellite has been used. Also, for plotting consistent maps, necessary regression equations were determined using the mean annual rainfall and temperature data, and by making a series of calculations in the ArcGIS software, a digital elevation map prepared from the area in a 90-pixel, was used.

\subsection{Area Zoning of Coastal Areas Using Climatic Data}

In this study, climatic parameters of precipitation and temperature as the selected indicators for assessing the status of the region from the point of view of precipitation and temperature variations for the port of Jask station and 17 years of climate data from the synoptic station have been used. To do this, first, using SPSS software and Kolmogorov-Smirnov statistical test, the rainfall and temperature distribution data were analyzed. After examining the results, the least amount of data was extracted on each scale during the statistical period and its coverage maps in each scale during the statistical period, the Arc Map is drawn. Then, after the calculations, the results of the various interpolation methods of IDW and Kriging with a weighing power of one to five were evaluated. Also, for a better and more accurate assessment of coastline changes, using the MODIS satellite data from 2006 to 2016, the coastline of Makran has been reviewed.

\section{Results and Discussion}

\subsection{Determining the Type of Climate in the Study Area}

In order to calculate the Embereger relationship, the three following parameters are needed: average temperature of the coldest and warmest month of the year, and the mean precipitation (in millimeters). Despite the mentioned parameters, the relationship was calculated and based on Table 3, the climate of the study area was determined. According to the calculations performed to determine the climatic condition of the Embereger method, it was found that the port of Jask and the coastline are dry to semi-arid zones. Of course, the beach strips are more volatile than the area, and there is no barrier to building offshore areas. Secondary method, which is a more convenient way to determine the type of climate in most regions of the country, uses the annual average of rainfall and temperature in the area for this purpose. Using the calculations done by the method of the De Martonne, the area has a dry to semi-arid state. The corresponding coastal strip has high evaporation due to extreme temperature fluctuations and precipitation and proximity to the equator. Table 4 shows the results of calculations of the De Martonne method based on Jask's synoptic station.

Table 3. Embereger Formula Calculation and Regional Climate Determination

\begin{tabular}{cc}
\hline Results & Climate Type \\
\hline $\mathrm{Q}<28$ & Dry \\
$8>\mathrm{m}>5.1$ & Hot \\
\hline
\end{tabular}


Table 4. De Martonne Formula Calculation and Regional Climate Determination

\begin{tabular}{cc}
\hline Results & Climate Type \\
\hline $\mathrm{I}<10$ & Dry \\
\hline
\end{tabular}

\subsection{Review the Process of Precipitation and Tem- perature Changes}

In order to better match and to better characterize the result obtained from the relations between Embereger and De Martonne, the diagram of precipitation and temperature variations in the region and the coastal strip is drawn up (Figures 1 and 2). According to the precipitation fluctuation chart, in this coastal strip the range of precipitation variation between 5 and $12 \mathrm{~mm}$ is very common. On the other hand, by examining the temperature changes, the 17 -year average for this port was 26 degrees. This amount of temperature is very important during the year from the examination of rainfall conditions and situation in the area. As this temperature shows that in the area and coastline the evaporation phenomenon is common in most of the year, and this evaporation is unavailable due to the lack of a coherent source such as a mountain that can enter the region's hydrological cycle again with cooling. This low rainfall it can also be concluded from the sea currents and the climatic conditions that cause rainfall in the coastal regions; therefore, it can be concluded from Embereger and De Martonne 's relations that the climate of the region is dry. It should also be noted that during the period from 2000 to 2007, temperatures were high, but this temperature dropped by 2 degrees in 2017. Of course, these climatic conditions can have an impact on coastal factors, so that many projects in the coastal areas do not have much progress.

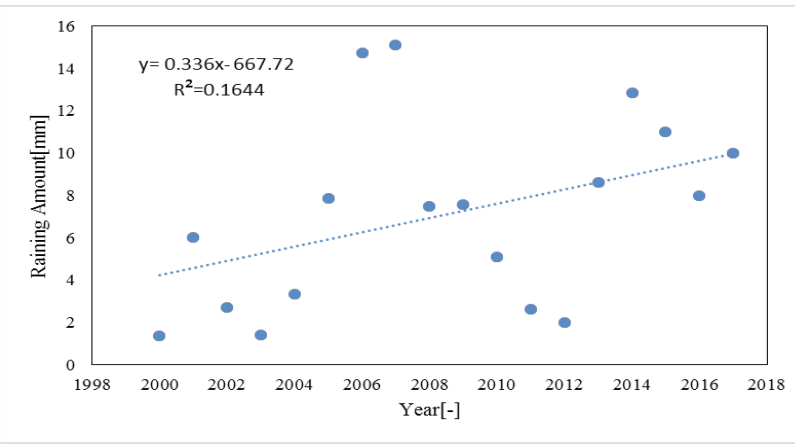

Figure 1. Raining Changes in Jask plot

\subsection{Check the Topography and Tilt of the Area}

Considering the conditions studied in the temperature variation and precipitation of the coastal strip, it is necessary that the area be considered in terms of topographical features and other effective factors considering the strategic nature of the Jask area, especially the Makran coast. In Figure 3, the map of the area and the coastal strip is specified. According to the map, you can see the role of temperature and precipitation in the region. Coastal areas are up to kilometers without mountains and highlands, which can be attributed to precipitation shortages in the region and high temperatures. However, according to the map, the existence of plains and coastal areas with a slope of less than 9 percent, as well as the existence of gorgeous rivers and natural attractions in the region provide a great opportunity to build tourist and recreational areas along the Makran coastline.

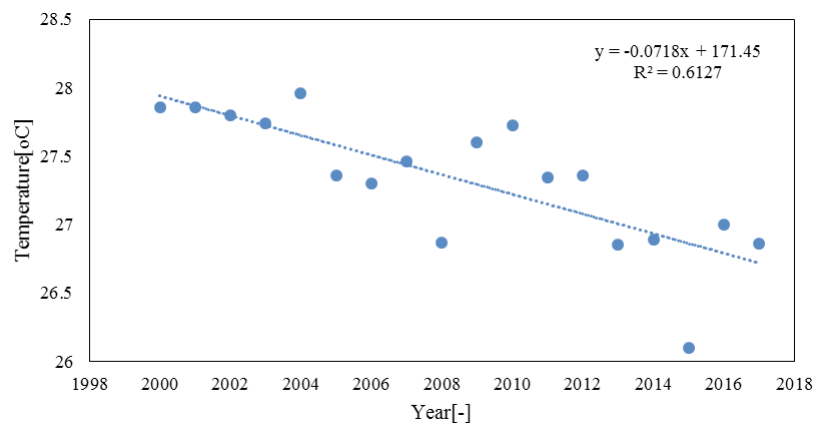

Figure 2. Temperature Changes in Jask Plot

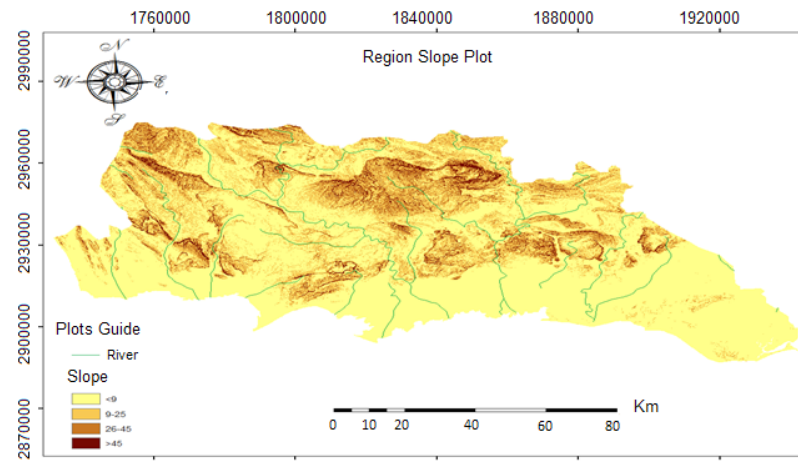

Figure 3. Regional Topology and Slope Plot

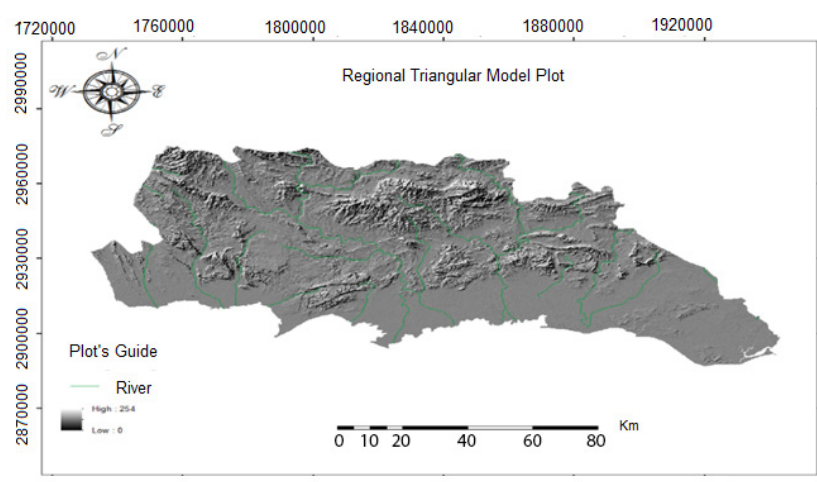

Figure 4. 3D View from Region 
Further, Arc Hydro software has been used to more accurately assess the status of the area, the existing rivers, and follow up of surface water behaviors on the route. Figure 4 shows the image obtained from this software.

Using the GIS software and measurement tool, it is also possible to predict the status of the region and the coastline using hydrological and climatic data. For this purpose, Arc Hydro, one of the options available in the ArcGIS software, has been used based on the digital map of the area, the status of the Arctic and the rivers. This software, which has been shown in Figure 5, has a high ability to determine and assess the physiological characteristics of the region. In this picture, the coastal strip has the proper features for implementing many economic projects in the region.

For more accurate evaluation of temperature and precipitation fluctuations in the area and coastal strip, consistent maps and homogeneous maps were provided with topographic maps, data obtained from the Jask port's synoptic station, and made by a series of calculations in ArcGIS software (Figures 6 and 7).

According to the regional map of the area, there is a higher rainfall in the central parts of the port of Jask and there is no shortage of factors in the coastal areas to avoid evaporation, but the amount of precipitation is lower than other areas. In the entire coastal zone of Makran, this issue is clearly visible. According to the coherent map, the coastal strip has a higher temperature than the central and upland areas of the port of Jask. This state of affairs treats the situation in the region to a large extent, as the high temperature conditions associated with humidity disrupt many activities in the region.

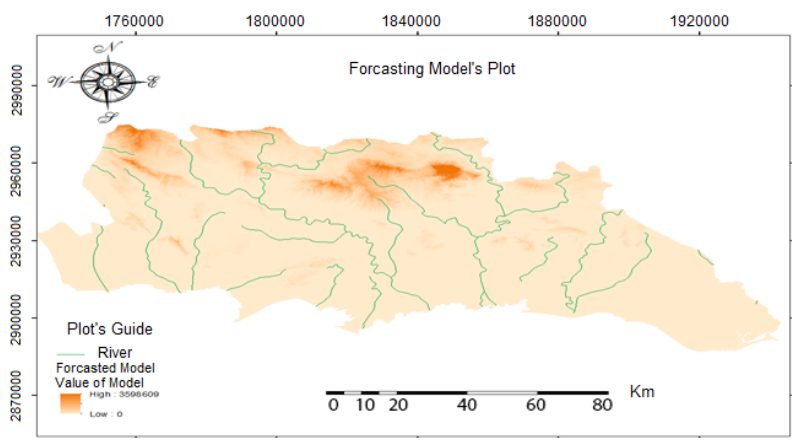

Figure 5. Forecasted Model using Hydrological and Climatic Derived from ArcGIS

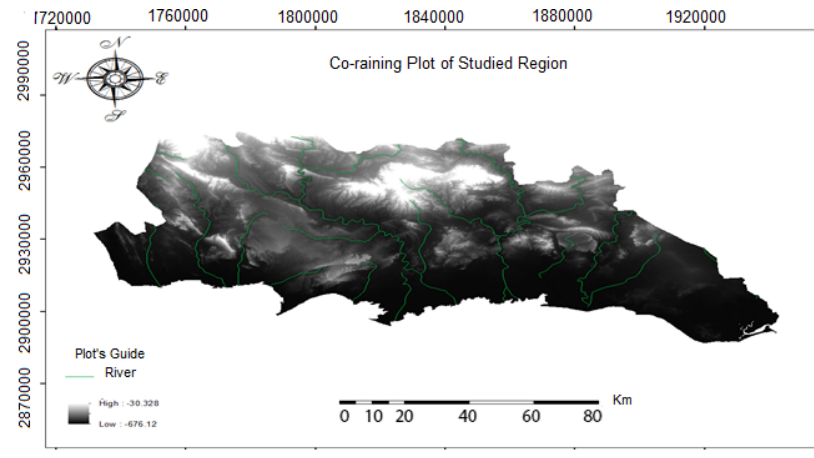

Figure 6. Co-raining Plot of Jask

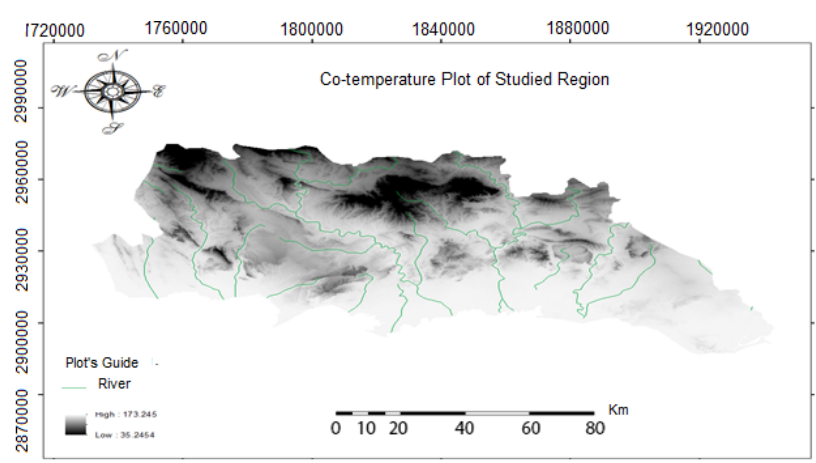

Figure 7. Co-temperature Plot of Jask

\subsection{Coastal Zoning Using Climatic Data}

In this study, climatic parameters of rainfall and temperature have been used as indicators for determining the status of the region. To do this, we first used the Kolmogorov-Smirnov test to investigate the rainfall distribution data and temperature of the area, and the results are presented in Tables 5 to 7. Considering the significant level (P) of more than 0.05 (for rainfall data equal to 0.13 and for temperature data equal to 0.093), data from rainfall and temperature have a good level of coastline level; Therefore, rainfall and temperature data are normal and a parametric test can be applied to these data. After reviewing the output results, the least amount of data was extracted on each scale during the statistical period and its coverage maps were plotted in Arc Map for each scale during the statistical period. After calculating, the results of various interpolation methods for IDW and Kriging with a weighing power of one to five were evaluated. Among interpolation methods, the two-dimensional weighted photo-IDW method with the least power for rainfall parameters and temperature the error value of the RMSE and MAPE and MBE errors are much more than other zoning methods. The lowest RMSE estimate for each of the indices with respect to the potentials is 0.22 and 0.4 respectively. Hence, this method is the most appropriate method for zoning the status of water resources in the Makran region and the

DOI: https://doi.org/10.36956/sms.v2i2.329 
coastal strip. The rainfall and temperature zone maps were also prepared in the coastal zone by precipitation and temperature data (Figures 8 to 11). Investigation of the maps shows that the coastline has the least rainfall distribution and the highest dispersion in the highlands of the port of Jask but according to the temperature zoning map, in the coastal areas, the highest amount of dispersion and the lowest temperature in the highlands. Coastal areas, such as high temperatures and high evapotranspiration, are in a state of inferiority, so that many projects are not in this situation.

Table 5. Result of Kolmogorov-Smirnov Test for Raining Data using Software SPSS One-Sample Kolmogorov-Smirnov Test

\begin{tabular}{lll}
\hline & & $\mathrm{V} 1$ \\
\hline $\mathrm{N}$ & & 17 \\
Normal Parameters $^{\mathrm{a}, \mathrm{b}}$ & Mean & $7.42145061728395 \mathrm{E} 0$ \\
& Std. Deviation & $4.186981284660888 \mathrm{E} 0$ \\
& Absolute & 0.113 \\
Most Extreme Differences & Positive & 0.113 \\
& Negative & -0.081 \\
Kolmogorov-Smirnov Z & & 0.481 \\
Asymp. Sig. (2-tailed) & & 0.975
\end{tabular}

a. Test distribution is Normal.

b. Calculated from data.

Table 6. Result of Kolmogorov-Smirnov Test for Temperature Data using Software SPSS One-Sample Kolmogorov-Smirnov Test

\begin{tabular}{lll}
\hline & & $\mathrm{V} 1$ \\
\hline $\mathrm{N}$ & & 17 \\
Normal Parameters ${ }^{\mathrm{a}, \mathrm{b}}$ & Mean & $2.72981372549020 \mathrm{E} 1$ \\
& Std. Deviation & 0.485733938643530 \\
& Absolute & 0.149 \\
Most Extreme Differences & Positive & 0.093 \\
& Negative & -0.149 \\
$\begin{array}{ll}\text { Kolmogorov-Smirnov Z } \\
\text { Asymp. Sig. (2-tailed) }\end{array}$ & 0.613 \\
\hline $\begin{array}{l}\text { a. Test distribution is Normal. } \\
\text { b. Calculated from data. }\end{array}$ & & 0.847 \\
\hline
\end{tabular}




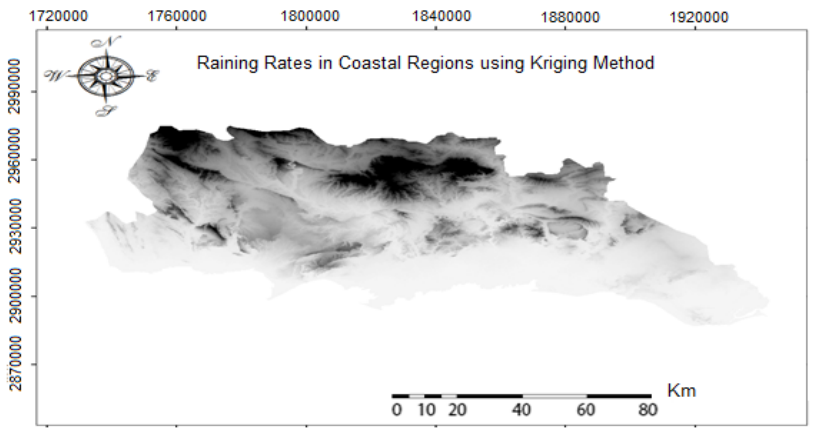

Figure 11. Regional Raining Plot for Jask and Makron Coast using Kriging Method

\subsection{Changes in Lines of the Makran Coast}

In this study, the changes in the Makran coastline were reviewed using MODIS satellite data between 2006 and 2016. In Figure 12, the accuracy of the measured data can be seen in the extent and evolution of the Oman Sea in the coastal strip of Makran. In Figure 13, coastline changes were monitored for three consecutive years between 2014 and 2016. Assessing the amount of seafront progress or resettlement can certainly be important in making decisions for the construction of residential and commercial areas.

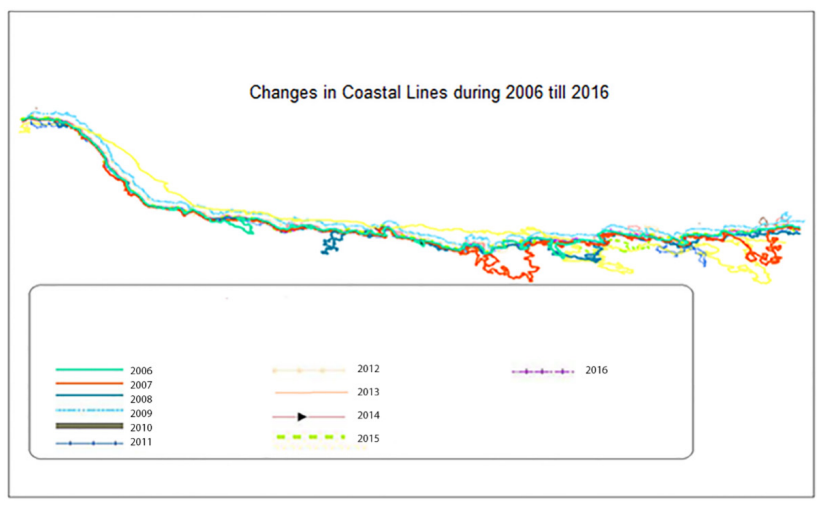

Figure 12. Changes in Coastal Lines during 2006 till 2017

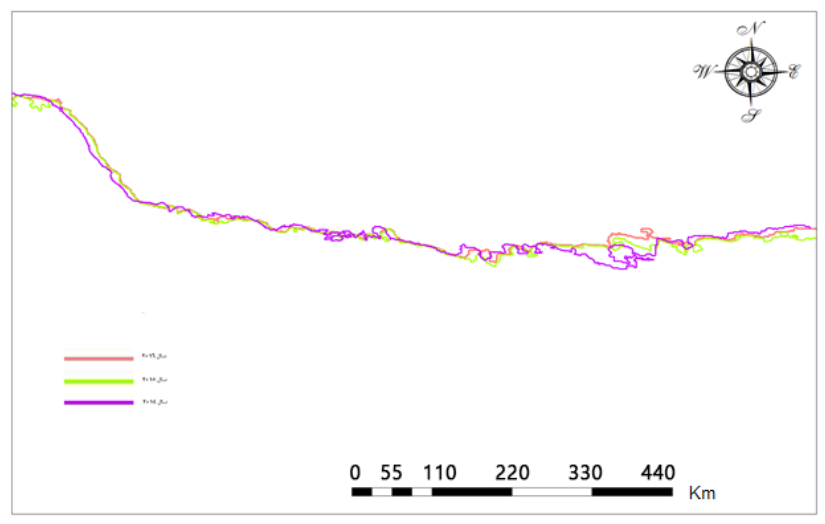

Figure 13. Changes in Makran Coast during 2014 till 2016

\section{Conclusions}

The climate of the studied area was determined by Embereger and De Martonne methods and 17 years of climatic data obtained from the synoptic station of port of Jask. According to the calculations carried out with the parameters of the warmest and coldest months of the year, it was found that the port of Jask is arid to semi-arid. The process of rainfall and temperature changes also indicates that in most days of the year, the phenomenon of evaporation is common in the region and coastal strip, and this evaporation is due to the lack of a coherent source such as mountains and suitable flows to create an outdated hydrological cycle and this low rainfall can also be deduced from sea currents and climatic conditions that cause rainfall in coastal areas. Of course, the beach strips are more volatile than the area, and it should not be difficult to construct sea areas according to the conditions. Considering the geographical conditions, scoring and determining the relevant criteria, the central part to the east of the Makran coast has a high value from the point of view of the creation of maritime conditions. This area is also suitable for hydraulic topography. In order to more accurately assess the precipitation and temperature conditions, the region was also examined for topographic properties. The obtained maps indicate that the coastal areas have the lowest tilt and topography that is very flat and smooth, up to kilometers without mountains and highlands, but, according to the map, the existence of plain and coastal areas with a slope of less than nine percent As well as the presence of rainy rivers and natural attractions in the region, it has provided very good conditions for the construction of new sea areas along the Makren coastline. With the possession of topographic maps and data on temperature and precipitation, we developed consistency maps. According to the regional map of the area, there is a higher rainfall in the central parts of the port of Jask and there is no limiting factor in coastal areas as a way of preventing the evaporation from wasting. The amount of precipitation is lower than other areas. According to the coherent map, the coastal strip has a higher temperature than the central and upland areas of the port of Jask. This state of affairs treats the situation in the region to a large extent, as the high temperature conditions associated with humidity disrupt many activities in the region. According to the topographical and hydrological conditions of the Makran coast, the zoning of the coastal areas is favorable and suitable so the geographical and natural parameters are effective in determining the status of the coast and zoning. In this study, regional distribution of coastal areas was performed using SPSS software and Kolmogorov-Smirnov test to analyze 
rainfall and temperature data of the region. The results showed that the data from rainfall and temperature have a good significance at the coastal level, so the rainfall and temperature data are normal and the parametric test can be applied to these data. After calculating the results of various interpolation methods for IDW and Kriging with a weighing power of one to five, it was found that the weight difference method (IDW) with a power of two for rainfall and temperature parameters had the lowest RMSE error and MAPE and MBE errors compared to other methods are zoning. Rainfall and temperature zone maps were also prepared in the coastal zone by rainfall and temperature data. Investigation of the maps shows that the coastline has the least rainfall distribution and the highest dispersion in the highlands of the port of Jask but according to the temperature zoning map, in the coastal areas, the highest amount of dispersion and the lowest temperature in the highlands. Coastal areas, such as high temperatures and high evapotranspiration, are in a state of inferiority, so that many projects are not in this situation.

Valuing and determining the appropriate points for the expansion of the marine areas, according to the views of the relevant experts in the field of marine science, can be an appropriate option. Multi-criteria methods can also provide good and precise results by prioritizing and weighting different parameters. Ultimately, the development of the Makran coast, despite some restrictions, is a national, regional and even international imperative. Development of basic facilities and expansion of commercial and recreational infrastructure can lead to national development in addition to improving the situation in the south-east region of Iran. Therefore, identifying and studying factors affecting the region's situation can be important in many aspects.

\section{References}

[1] Macleod \& Congalton, 1998, Analysis of barrier shoreline change in Louisiana from 1853 to 1989. Atlas of shoreline changes in Louisiana from, 36-97.

[2] Jensen, 1996. Shoreline change along, Remote Sensing, 3(7): 1516-1534.

[3] Zafar Ullah, Wen Wu, Peifang Guo, Jing Yu, A study on the development of marine functional zoning in China and its guiding principles for Pakistan Ocean \& Coastal Management, Volume 144, 15 July 2017, Pages 40-50.

[4] Pravin D. Kunte, Nitesh Jauhari, Utkarsh Mehrotra, Mahender Kotha, Alexandre S. Gagnon, Multi-hazards Coastal vulnerability assessment of Goa, India, using geospatial techniques Ocean \& Coastal Management, Volume 95, July 2014, Pages 264-281
[5] Wang Chunye, Pan Delu, Zoning of Hangzhou Bay ecological red line using GIS-based multi-criteria decision analysis Ocean \& Coastal Management, Volume 139, April 2017, Pages 42-50

[6] Lien-Kwei Chien, Wen-Chien Tseng, Chih-Hsin Chang, Chih-Hsiang Hsu, A study of ocean zoning and sustainable management by GIS in Taiwan Ocean \& Coastal Management, Volume 69, December 2012, Pages 35-49

[7] Ling Ou, Wei Xu, Qi Yue, Chang L. Ma, Yue E. Dong, Offshore wind zoning in China: Method and experience Ocean \& Coastal Management, Volume 151, 1 January 2018, Pages 99-10

[8] Donny \& Singh, 1989, Shoreline changes along the Rosetta-Nile promontory: monitoring with satellite observations, Marine Geology, 99(1): 67-77.

[9] Gleissy Mary Amaral Dino Alves dos Santos, Alexandre Rosa dos Santos, Luciano José Quintão Teixeira, Sérgio Henriques Saraiva, Rodrigo Scherer, GIS applied to agriclimatological zoning and agrotoxin residue monitoring in tomatoes: A case study in Espírito Santo state, Brazil Journal of Environmental Management, Volume 166, 15 January 2016, Pages 429-439

[10] Gonzalo Hernán Camba Sans, Sebastián Aguiar, María Vallejos, José María Paruelo, Assessing the effectiveness of a land zoning policy in the Dry Chaco. The Case of Santiago del Estero, Argentina Land Use Policy, Volume 70, January 2018, Pages 313-321

[11] Zhiming Zhang, Ruth Sherman, Zijiang Yang, Ruidong $\mathrm{Wu}$, Xiaokun $\mathrm{Ou}$, Integrating a participatory process with a GIS-based multi-criteria decision analysis for protected area zoning in China Journal for Nature Conservation, Volume 21, Issue 4, August 2013, Pages 225-240

[12] Suzanne J. Boyes, Michael Elliott, Shona M. Thomson, Stephen Atkins, Paul Gilliland, A proposed multiple-use zoning scheme for the Irish Sea.: An interpretation of current legislation through the use of GIS-based zoning approaches and effectiveness for the protection of nature conservation interests Marine Policy, Volume 31, Issue 3, May 2007, Pages 287298

[13] Muhammad Atiq Ur Rehman Tariq, Nick van de Giesen, Floods and flood management in Pakistan Physics and Chemistry of the Earth, Parts $\mathrm{A} / \mathrm{B} / \mathrm{C}$, Volumes 47-48, 2012, Pages 11-20

[14] Qinhua F., Ran Z., Luoping Z., Huasheng H., Marine Functional Zoning in China: Experience and Prospects, Journal Coastal Management Volume 39, 2011 - Issue 6, 2011 Pages 656-667

[15] Michelle E. P., Zoning design for cross-border ma- 
rine protected areas: The Red Sea Marine Peace Park case study, Ocean \& Coastal Management 2007, 499-522

[16] Qinhua F., Deqiang M., Liyu Z., Shouqin Z., Marine functional zoning: A practical approach for integrated coastal management (ICM) in Xiamen, Ocean \& Coastal Management, 2018

[17] Ahrari Roudi M., Moussavi-Harami R., Lak R.,
Mahboubi A., Motamed A., Sedimentology-environmental assessment of the Makran coastal region of Iran., Journal of Applied Geology Autumn 2011, Vol. 7, No. 4.

[18] Haghipour N., Jean-Pierre B., Geomorphological analysis of the drainage system on the growing Makran accretionary wedge., Geomorphology, Volume 209, 15 March 2014, Pages 111-132 